Europe's Journal of Psychology 1/2009

www.ejop.org

\title{
Prolonged Video Viewing and Emotional Intelligence: An experimental investigation on Preadolescents
}

\author{
Simerpreet Ahuja \\ Research Scholar \\ School of Management \& Social Sciences, Thapar University \\ Santha Kumari \\ Associate Professor \\ School of Management \& Social Sciences, Thapar University
}

\begin{abstract}
The present study investigated the nature and extent of relationships between prolonged hours of video viewing and emotional intelligence in preadolescents ( $n=400$ ). The Video Viewing Questionnaire and BarOn Emotional Quotient Inventory: Youth Version were used to measure video viewing habits and emotional intelligence scores. The results revealed that the two gender groups differed significantly in the mean scores. In addition to this overall EQ, a detailed analysis of each component of the scale was also done. The relationship between emotional intelligence and video viewing was found to be stronger in females as compared to males. The findings are explained in terms of the theories associated with the process of child development such as cultivation hypothesis, alienation hypothesis, and social learning hypothesis.
\end{abstract}

Key words: extended video viewing, emotional intelligence, preadolescents, adaptability, and assertiveness.

Today children are growing up in a technological environment that includes an element of daily visual stimulation which has become an essential part of human experience. Almost all new media, including radio, television, computer and internet are considered to have a potential positive and negative influence on children. Children have been treated as the most vulnerable agents of media influence. The mass media can be regarded as a socializing agency in addition to the family and education (McQuail, 2000). 
The studies have shown that with the onset and advancement of electronic media like satellite, cable TV and the internet, there has been an upsurge in the media consumption of children and adolescents (Comstock \& Scharrer, 2001; Groebel, 2001; von Feilitzen, 1999). Media has a significant presence in most of human environment (Gentile \& Walsh, 2002). Media critics have proclaimed that children's use of these sources may affect their personal lives, family relationships and peer adjustment. This article offers a set of scenarios depicting young media users under a variety of conditions resulting in different kinds of children's behavioral patterns.

Video viewing hinders the emotional, social and intellectual development of young children. Rubin (1985) argued that TV viewing is often used for companionship or to battle loneliness. Consequently, television may have an obvious impact on how people initiate and maintain interpersonal relationship. However, in less than 20 years, a TV could be found in the majority of homes. Today, over $90 \%$ of the homes have at least two TVs. Accordingly, Gerbner, Gross, Morgan, and Signorelli (1986) see television as the great common experience. Television causes a culture to become homogenized. This effect is known as cultivation effect.

Due to the high volume use of e-mail, chat rooms, and bulletin boards for interpersonal relationship purposes, considerable interest has focused on this medium. American On-line is said to carry over 13 million e-mail messages daily (Lawe, 1997). Parks and Floyd (1996) report that people are using e-mail and bulletin boards to initiate and develop relationships (Stafford, Kline, \& Dommick, 1999). Their data suggest that on-line relationships develop in a similar fashion to those formed in face-to-face interaction. In sum, the growing dependence on technology is allowing each individual to become more and more "self-sufficient". This gained autonomy has allowed the individual to become more isolated and reclusive. The need for social contact, in many cases, is being fulfilled by the media - especially television. Relationships are not being initiated with "real" people, but with the projected, edited, "spun" images the users share on-line. As Shakespeare noted, "all the world's a stage, and all the men and women merely players" (As You Like It. Act ii, Sc. 7). However, unlike the parts that Shakespeare envisioned men and women playing, the computer-aged players may aspire to act-out scripts less representative of our humanity.

Matsuda (2001) suggests that the mobile platform has significantly lowered the quality of communication because "consumer related communication" and "brief messaging (just to kill time)" have been identified as the main uses of mobile-related communications. The social influence model of technology use points out that "individuals' media perceptions and use are, in part, socially constructed" (Schmitz \& 
Fulk, 1991). The model proposes that people around the user influence the user's perception of the medium, including its usefulness, and that a user's skills and experience of the communication technology facilitate use of the medium (Tanaka, 2001). Computer use can strongly influence the degree to which students collaborate with their peers, which in turn may well influence what and how they learn (Hawkins, 1984). Internet addiction was significantly associated with depressive symptoms and obsessive-compulsive symptoms, high harm avoidance, low selfdirectedness, low cooperativeness and high self-transcendence ( $\mathrm{Ha}$, Kim, Bae, Bae,Kim, Sim, etal, 2007). Internet addiction exhibit more impulsivity than controls and have various co morbid psychiatric disorders (Cao, Su, Liu, Gao, 2007).

Low Internet users, as compared with high users, reported better relationships with their mothers and fathers (Sanders, Field, Diego, Kaplan, 2000). Kraut, Patterson, Lundmark, Kiesler, Mukopadhyay, and Scherlis (1998) reported that heavy use of the Internet is related to the experience of loneliness among users. Turkle (1996) showed that the use of the Internet is likely to result in social isolation. Kraut etal (1998) reported that the use of the Internet is likely to result in an increase in depression and loneliness. For many of the young people the internet has become 'their world' within which different criteria for success can operate. It seems that young people need a 'safety valve' from the demands of their parents and schools and the internet has given them this opportunity. They have created their, so-called, 'own world' on the internet, a place where they can talk freely (Whang \& Jang, 2002). The effects of media, such as television, video games and movies on family life have also been demonstrated, and these media will effect personal and social development (Huston et al., 1992; Larson, 1995).

Watt and White (2000) also postulate that adolescents who tend to socially isolate themselves are at risk of becoming absorbed into the "safe" world of cyberspace, where they can finally interact socially without some of the inhibitors of interacting personally face to face. Consequences for the child of extensive viewing may include problems of mood, behavior, and learning, and poor health outcomes (Owens, 2004). In an extensive report on children and computers, the Alliance for Childhood contended that computers could hamper physical, emotional and intellectual development in children (Cordes \& Miller, 2000). Larson (1995) found that some people view television as a means to isolate themselves and "tune out the world." Similarly, the Internet provides an opportunity for people to engage in online infidelity which detracts from primary relationships (Young, 2000).

Internet use can be highly time consuming and can lead to Internet addiction (Young, 2004) and limited social interaction with others (i.e., social isolation; Sanders, 
Field, \& Diego, 2000). The lack of feeling limits intimacy development directly, as intimacy is multifaceted and involves an emotional intimacy component (Erikson, 1968). With the prevalence of media and technology in society and the average home, it is predictable that a person that lacks keen awareness of self and self worth would be more likely to borrow self from fictional characters depicted in the media. It may also be that poorly differentiated persons may spend more time with media seeking to learn more socially desirable traits (i.e., more of what others expect) rather than seeking to develop true individual identity.

Research suggests that people use media to escape from social interactions. Television has been called an "invisible family member" that provides a source of companionship (Gerbner, Gross, Morgan, \& Signorelli, 1986; Bryant \& Bryant, 2001). The longer we live with television, the more invisible it becomes. As the number of people who have never lived without television continues to grow, the medium is increasingly taken for granted as an appliance, a piece of furniture, a storyteller, a member of the family.

Due to these and many other reasons, excessive video viewing is a serious handicap to the development of young children. Preadolescence is a period of development and consolidation of the self, of one's identity and understanding of the self in relation to social world (Coleman and Hendry, 1990). Relationships with peers, family and society go through distinct changes during this time. The child begins to assert more autonomous control over their decisions, emotions and actions, and start to disengage from parental control. At the same time, the school context involves an intense socialization process during which preadolescents become increasingly aware of the perspectives of classmates, teachers and societal influences (Berzonsky \& Adams, 2003). Several studies provide preliminary evidence that video viewing has positive impact on children's development. The literature in elementary education and in child psychology shows that the age roughly from nine until puberty is the forgotten period of childhood. It is a no- man's land as far as research is concerned. So it's essential to study this period of development which is considered to be a critical period. The present study is an attempt to analyze the detrimental impact of excessive video viewing on affective development of preadolescents. It is purely an experimental study which adds support to the existing evidences and directions for the future research.

It was hypothesized that heavy viewers may perform poor than light viewers on emotional quotient. 
Method

Design

A 2(sex: male, female) x 2(category: light viewing, heavy viewing) ANOVA was carried for all variables studied.

Participants

One thousand and six hundred preadolescents (male $=900$; female $=700$ ) studying in various schools of Punjab participated in this study. A video viewing questionnaire was used to categorize subjects into light and heavy video viewers. Those who viewed less than 12 hours per week were categorized as light viewers and more than 20 hours were categorized as heavy viewers. The third category of medium viewers comprised of 13-19 hours of video viewing. The participants of medium category ( $N$ $=1200$ ) were excluded from the study as the main objective of the study was to compare the extreme categories, heavy and light viewers. The remainder of the participants ( $N=400$ ) were further tested on Emotional quotient. Participants ranged in age from 9 to 12 years. Socioeconomic status, Intelligence and education levels and abnormalities were controlled. The consent of parents was sought for testing children on all measures. The participants were given educational materials as incentives for participation. The heavy viewers $(N=200)$ and light viewers $(N=200)$ were tested on all measures individually.

Measures

Video Viewing Questionnaire: A Video Viewing Questionnaire was used to select two categories of subjects, light video viewers and heavy video viewers. It consisted of 21 items to elicit the number of hours children watched television and used computer per week. It also contained items to rule out any kind of congenital disorders such as mental retardation, epilepsy etc. The questionnaire was sent to parents to be filled by them. The light and heavy viewing categories were chosen on the basis of Mean (16.2) and SD (7.92) values of 1600 children who were surveyed to study their video viewing habits. Half standard deviation above and below the mean were categorized as heavy viewers and light viewers respectively.

BarOn Emotional Quotient Inventory: Youth Version (BarOn EQ-i: YV): This inventory was developed by Reuven Bar-On and James D.A. Parker (2006). It is an easily administered self report instrument designed to measure emotional intelligence in 
young people aged 7-18 years. The BarOn EQ-i: YV consists of 60 items that are distributed across 7 scales namely total emotional intelligence, interpersonal scale, intrapersonal scale, adaptability scale, stress management scale, general mood scale and positive impression scale. The BarOn EQ-i: YV is a 4-point Likert type scale. The higher score indicates increased levels of emotional intelligence.

Results

Emotional quotient

On Emotional Quotient Inventory, heavy viewers performed poor compared to light viewers. The mean scores for heavy viewers were 90.06(SD=15.81) and 88.52 $(S D=13.05)$ for boys and girls respectively. And for the light viewers, the mean was 99.96 (SD=14.46) for boys and 100.27 (15.61) for girls. The data of the Emotional quotient was analyzed using $2 \times 2$ ANOVA. The main effect of video viewing is significant $(F(1,396)=55.59, P<.0001)$, however the effect of sex and interaction effect are not significant. The simple effect analysis reveals that video viewing has significant affect on females $(F(1,396)=32.746, p=0.001)$ as compared to males ( $F$ $(1,396)=23.246, p<0.001)$. This shows that females are more affected as compared to males.

\section{Emotional quotient (Intrapersonal scale)}

In Intrapersonal scale, heavy viewers performed poor compared to light viewers. The mean scores for heavy viewers were 102.45 (SD=10.91) and 100.84 (SD=12.34) for boys and girls respectively. And for the light viewers, the mean was 105.77 (SD=15.37) for boys and 103.70 (17.75) for girls. The data of the Emotional quotient (Intrapersonal scale) was analyzed using 2x2 ANOVA. The main effect of video viewing is significant $(F(1,396)=4.51, p<.05)$. However, the effect of sex and interaction effect are not significant. The simple effect analysis reveals that there is significant sex difference in high video viewing category $(F(1,396)=9.669, p<.0001)$.

Emotional quotient (Interpersonal scale)

In Interpersonal scale, heavy viewers performed poor compared to light viewers. The mean scores for heavy viewers were 86.43 (SD=13.30) and 84.06 (SD=14.32) for boys and girls respectively. And for the light viewers, the mean was 92.36 (SD=14.67) for boys and 93.6 (14.40) for girls. The data of the Emotional quotient (Interpersonal scale) was analyzed using 2x2 ANOVA. The main effect of video viewing is 
significant $(F(1,396)=29.74, p<.0001)$, however the effect of sex and interaction effect are not significant. The simple effect analysis reveals that the effect of video viewing is significant for females $(F(1,396)=21.65, p<.0001)$ as compared to males $(F$ $(1,396)=8.74, p<.0001)$.

\section{Emotional quotient (Stress management scale)}

The Mean and SD of Stress management scale scores of heavy and light viewers for both boys and girls were computed. Heavy viewers performed poor compared to light viewers. The mean scores for heavy viewers were 89.55 (SD=10.51) and 88.15 $(S D=11.16)$ for boys and girls respectively. And for the light viewers, the mean was 89.94 (SD=13.46) for boys and 90.79 (12.43) for girls. The data of the Emotional quotient (Stress management scale) was analyzed using 2x2 ANOVA. The main effect of video viewing, sex and interaction effect are not significant. The simple effect analysis reveals there is sex difference in high viewing category $(F(1,396)$ $=7.867, \mathrm{p}<.0001)$.

\section{Emotional quotient (Adaptability scale)}

On Adaptability scale, heavy viewers performed poor compared to light viewers. The mean scores for heavy viewers were 99.15 (SD=14.92) and 94.25 (SD=13.86) for boys and girls respectively. And for the light viewers, the mean was 103.15 (SD=13.16) for boys and 101.39 (15.43) for girls. The data of the Emotional quotient (Adaptability scale) was analyzed using $2 \times 2$ ANOVA. The main effect of video viewing is significant $(F(1,396)=15.02, p<.0001)$. However, the effect of sex and interaction effect are not significant. In simple effect analysis, the effect of video viewing is more on females $(F(1,396)=12.339, p<.0001$ as compared to males $(F(1,396)=3.87, p<.05)$. The effect of sex is significant in high viewing category $(F(1,396)=5.811, p<.05)$.

\section{Emotional quotient (General Mood scale)}

In General Mood scale, heavy viewers performed poor compared to light viewers. The mean scores for heavy viewers were 90.74 (SD=13.32) and 90.05 (SD=10.55) for boys and girls respectively. And for the light viewers, the mean was 93.61 (SD=11.42) for boys and 94.48 (SD=13.84) for girls. The data of the Emotional quotient (General Mood scale) was analyzed using 2x2 ANOVA. The main effect of video viewing is significant $(F(1,396)=8.718, p<.003)$, however the effect of sex and interaction effect are not significant. The simple effect analysis reveals the effect of video viewing is more on females $(F(1,396)=6.420, p<.05)$ as compared to males. 


\section{Discussion}

The findings confirmed the proposed hypothesis that heavy viewers may perform poor compared to light viewers on emotional intelligence. In addition to this, sex difference in emotional quotient was also found. The findings of this study can be explained in terms of social learning theory and the cognitive theory (Bandura, 1986; Bandura, 1994). It states that novel behavior is acquired directly through experience or indirectly by observing such behavior that brings rewards to others through vicarious reinforcement. Repeated exposure to media teaches children novel behaviors that become part of their cognitive structure and behavioral repertoire. The cultivation hypothesis (Gerbner, Gross, Morgan, \& Sigoreilli, 1986; Bryant \& Bryant, 2001) also asserts that heavy television viewing leads to or cultivates perceptions of the world that are consistent with televisions portrayals, and television provides a source of companionship. In sum, the growing dependence on technology is allowing each individual to become more and more "self-sufficient". This gained autonomy has allowed the individual to become more isolated and reclusive. The need for social contact, in many cases, is being fulfilled by the media - especially television. Relationships are not being initiated with "real" people, but with the projected, edited, "spun" images the users share on-line (Stafford, Kline, \& Dommick, 1999). Computer use can strongly influence the degree to which students collaborate with their peers, which in turn may well influence what and how they learn (Hawkins, 1984). This is also indicated by low scores on interpersonal scale. Media cultivates the meanings of social, personal and cultural contexts. It also assumes that heavy viewers are also less selective in their viewing, engage in habitual viewing and experience a good deal of sameness of the content. The child borrows the self from fictional characters depicted in the media and lacks keen awareness of self and self worth which hampers emotional attachments and primary relationships which explains the plausible cause for low scores of heavy viewers on intrapersonal scale.

The child development experts believe that the stimuli children receive and the activities they engage in during the first few years of life are critical not only for their physical well being but also for their social, emotional and cognitive development. Vygotsky $(1978,1986)$ argued that cognitive development did not just happen in the brain of the individual child, but depended on interactions between the child and cultural tools available for mediating knowledge. And in present era media and its components are major source of cultural tools which influence child development. Social behavior is controlled by programs or scripts that are acquired in childhood. The young children may also have more difficulty distinguishing reality from fantasy 
and may have a greater tendency to identify with and imitate media characters. Children find it difficult to separate televised fantasy from life reality (Wright, Huston, Reitz \& Piemyat, 1994).This supports the heavy viewers depicting low adaptability scores.

The video viewing displaces the child's imaginary play which has an important developmental function in helping the young child to understand mental states as desires and beliefs as entities that can be reasoned about and used to predict behavior (Lillard, 2002). Cognitive priming emphasize that watching negative feelings may trigger negative feelings which in turn prime other negative feelings, thoughts, memories and behavioral tendencies. Cognitive associative network affect the link between media activated thoughts and actual behavior (Jo \& Berkowitz, 1994).

Internet addiction was significantly associated with depressive symptoms and obsessive-compulsive symptoms, high harm avoidance, low self-directedness, low cooperativeness and high self-transcendence (Ha, Kim, Bae, Bae,Kim, Sim, etal, 2007). The low scores on general mood scale can be attributed to impact of prolonged video viewing and realed changes. Internet addiction exhibit more impulsivity than controls and have various co morbid psychiatric disorders (Cao, Su, Liu, Gao, 2007). Kraut, Patterson, Lundmark, Kiesler, Mukopadhyay, and Scherlis (1998) reported that heavy use of the Internet is related to the experience of Ioneliness among users. Turkle (1996) showed that the use of the Internet is likely to result in social isolation. They have created their, so-called, 'own world' on the internet, a place where they can talk freely (Whang \& Jang, 2002). The effects of media, such as television, video games and movies on family life have also been demonstrated, and these media will effect personal and social development (Huston et al., 1992; Larson, 1995). Consequences for the child of extensive viewing may include problems of mood, behavior, and learning, and poor health outcomes (Owens, 2004). The above description reason out and support that heavy viewers scored less on emotional intelligence.

Significant gender differences were also noted in emotional quotient. Females report higher scores on emotional intelligence as compared to males (Brachett, Rivers, Shiffman, Lerner \& Salovey, 2006). The results in this study indicate that video viewing has significant effect on girls even though boys also use computers, television. The plausible explanation may be that media portrayals exert stress and anxiety on females to grow up too quickly as there is growing checklist of ideals they have to adhere to. The girls are forced to grow at an unnatural pace in the society that is damaging their emotional well being. Sex role stereotypes in the media were 
responsible for young women's negative self concepts. This can be the plausible cause for low intrapersonal scores for females. Another reason is that girls view family drama and non aggressive programs which portray traditional roles. Females characters are more likely than males characters to be portrayed in traditional stereotypes such as being emotional, romantic, affective, and domestic (Thompson \& Zerbinos, 1995). Girls are reported to like violence less, approve of it less, and see it as less realistic, they are more frightened and distressed by media portrayals, respond to it more emotionally and watch it in a more involved and less detached way than boys do ( Van Evra, 1990). The low interpersonal and general mood scale scores for females can be attributed to the distressing influence of the media portrayals.

Another possible explanation for any gender differences may lie in the types of programs preferred by boys and girls. Boys prefer violent programs and girls prefer nonviolent programs. Exposure to video games, computer and television violence can serve as a proximate cause of aggression by influencing cognitive, affective and arousal variables. The desensitizing effect of media exposure is a reduction in empathy, generally defined as sensitivity to other's pain and suffering (Funk, Bechtoldt, Pasold \& Baumgadner, 2004). It is also reported that boys are more likely than girls to use media as a tool to increase their energy level and seek stimulation and girls use it for socialization. This can be attributed as the possible cause for male depicting high stress management scores. Research reports socialization pressures on girls to express their feelings and on boys to inhibit them. Boys are taught to be tough and brave, to mask their feelings, and girls on other hand are socialized to be nurturing. They are taught that anger is the only emotion socially acceptable for them to display and other emotions are stifled. Men are more likely than women to be portrayed as work oriented and women are more likely to be portrayed in home. Men are also more likely to deal with problems themselves while women are likely to seek help and to help others with their problems. This helps in developing independence and assertiveness in boys. All these evidences may be considered as contributing factors to high adaptability scores of males obtained in this study.

Research indicates that video viewing inhibits cognitive and motor skills and children with these delays are less able to cope with frustration and defer gratification. Valkenburg, Cantor, \& Peeters (2000) found that 7-12 years girls reported resorting to social support, physical intervention and escape more often than boys did, due to which girls may have a greater need for social approval. Girls also report more comfort in expressing emotions (Joshi \& Maclean, 1994). Inner speech is hypothesized to organize the child's internal cognitive activities and to regulate the child's external behavior. The self regulatory skills enable children to inhibit certain 
thoughts or actions. The girls are reported to have better inhibitory control as compared to boys. The evidence does confirm that girls show greater emotional expression than boys, they experience emotions more intensely, and they display more frequent expressions of emotions. Women are more willing to self disclosure about emotions and they see themselves and others see them, as expressing emotions more often and more intensely than men (Brody \& Hall, 2000; Cross \& Madson, 1997; Gross\& John, 1998). Women's faces are more spontaneously revealing of their emotions than men's faces are, and women are more successful in posing expressions of emotion than men are (Hall, 1984). Due to which females are unable to mask their emotions as males can do. This is revealed in low adaptability and interpersonal scores of females. The results indicate that girls are affected more by media as compared to boys as they understand, express their emotions effectively and assimilate emotional cues more easily.

The overall trend of the present findings is an indication that excessive video viewing is detrimental to the emotional growth of children. There are many preadolescents who spend a lot of time in video viewing. The ubiquitous nature of media in our children's lives and the potential harm from exposure to media messages and images is source of serious concern to parents, educators and policy makers. Parents should be encouraged to monitor what their children watch to make sure the messages are appropriate for their development.

\section{References}

Bandura, A. (1986). Social Foundations of Thought and Action: A Social Cognitive Theory. Englewood Cliffs, NJ: Prentice Hall.

Bandura, A. (1994). Social Learning Theory. From Theory into practice database. http://tip.psychology.org/bandura.html.

Bar-On, R. \& Parker, J.D. (2006). Technical Manual BarOn emotional Quotient Inventory: Youth Version. New York: Multi Health Systems.

Berzonsky, M. D., \& Adams, G. R. (2003). The Blackwell Handbook of Adolescence. Oxford Blackwell.

Brackett, M. A., Rivers, S., Shiffman, S., Lerner, N., \& Salovey, P. (2006). Relating emotional abilities to social functioning: A comparison of performance and self-report measures of emotional intelligence. Journal of Personality and Social Psychology, 91, 780-795. 
Brody, L. R., \& Hall, J. A. (2000). Gender, emotion, and expression. In M. Lewis \& J.M. Havilland- Jones (Eds.), Handbook of emotions (2nd ed., pp. 338-349). New York: Guilford.

Bryant, J., \& Bryant, J.A. (2001). Television and the American Family. United States. Lawrence Erlbaum

Cao, F., Su, L., Liu, T., \& Gao, X. (2007). The relationship between impulsivity and Internet addiction in a sample of Chinese adolescents. European Psychiatry, 22 (7), 466-471.

Coleman, J., \& Hendry, L. (1990). The Nature of Adolescence. Routledge, London \& New York.

Comstock, G., \& Scharrer, E. (2001). The use of television and other film directed media. In D. G. Singer \& J. L. Singer (Eds.), Handbook of children and the media (pp.47-72). Thousand Oaks, CA: Sage Publications.

Cordes, C., \& Miller, E. (Eds.) (2000). Fool's Gold: A critical look at computers in Childhood. College Park, MD: Alliance for Childhood.

Cross, S.E., \& Madson, L. (1997). Models of the self: Self- construals and gender, Psychological Bulletin, 122, 5-37.

Erickson. E. H. (1968). Identity: Youth and Crisis. New York: Norton.

Funk, J. B., Bechtoldt-Baldacci, H., Pasold, T., \& Baumgardner, J. (2004) Violence Exposure in Real-life, Video Games, Television, Movies, and the Internet: Is There Desensitization? Journal of Adolescence, 27, 23-39.

Gentile, D. A. \& Walsh, D. A. (2002). A normative study of family media habits. Applied Developmental Psychology, 23, 157- 178.

Gerbner, G., Gross, L., Morgan, M., \& Signoreilli, N. (1986). Living with television: The dynamics of the cultivation process. In J. Bryant \& D. Zillman (Eds.) Perspectives of media effects. Hillsdale, N.J: Lawrence Erlbaum

Groebel, J. (2001). Media violence in cross-cultural perspective: A global study on children's media behavior and some educational implications. In D. G. Singer \& J. L. Singer (Eds), Handbook of children and the media (pp. 255- 268). Thousand Oaks, CA: Sage Publications 
Gross. J. J., \& John, O. P. (1998). Mapping the domain of expressivity: Multimethod evidence for a hierarchical model. Journal of Personality and Social Psychology, 74, 170191.

Ha, J. H., Kim, S. Y., Bae, S. C., Bae, S., Kim, H., \& Sim, M. (2007). Depression and Internet addiction in adolescents. Psychopathology, 40 (6), 424 -430.

Hall, J. A. (1984). Nonverbal sex differences: Communication accuracy and expressive style. Baltimore: Johns Hopkins University Press.

Hawkins, J. (1984, April). Paired problem solving in a computer context. Paper presented at the meeting of the American Educational Research Association, New Orleans, LA.

Huston, A.C., Donnerstein, F.E., Fairchild, H., Feshbach, N., Katz, P., Murray, L.,

Rubinstein, E., Wilcox, B., \& Zuckerman, D. (1992). Big world, small screen: The role of television in American Society. Lincoln, NB: University Nebraska Press

Jo, E., \& Berkowitz, L. (1994). A priming effect analysis of media influences: An update. In J. Bryant \& D. Zillman (Eds.). Media Effects: Advances in theory and research (pp. 43-60). Hillsdale. NJ: Lawrence Erlbaum.

Joshi, M. S., \& Maclean, M. (1994). Indian and English Children's Understanding of the Distinction between Real and Apparent Emotion. Child Development, 65 (5), 1372-1384.

Kraut, P., Patterson, M., Lundmark, V., Kiesler, S., Mukopadhyay, T., \& Scherlis, W. (1998). Internet paradox: a social technology that reduces social involvement and psychological well-being? American Psychologist, 53, 65-77.

Larson, R. (1995). Secrets in the bedroom: Adolescent's private use of media. Journal of Youth and Adolescence, 24, 535-550.

Lawe, R. K. (1997). "Computer services 'warping' their way into common use." Columbus Dispatch, pp. 1-2.

Lillard, A.S. (2002). Pretend play and cognitive development. U. Goswami (Ed.), Handbook of cognitive development (pp. 188-205). London: Blackwell.

Mastuda, M. (2001): "University Students and the Use of Mobile Telephones", the Study of Socio-Information, Bunkyo University (in Japanese) from:

http://www10.plala.or.jp/misamatsuda/youth-mobile.html 
McQuail, D. (2000). Mcquail's Mass Communication Theory, 4th Edition, London, Thousand Oaks, New Delhi: Sage Publications.

Owens, J. A. (2004). The electronic sandman: the impact of the media on adolescent sleep. Sleep, 27(1), 101-104.

Parks, M. R., \& Floyd, K. (1996). "Making friends in cyberspace." Journal of Communication. 46, 80-97.

Rubin, A. M. (1985). "Media gratification through the life cycle." In K. E. Rosengren, L.A Wenner, \& P. Palmgreen (Eds.). Media gratification research: Current perspectives (pp. 195-208). Beverly Hills, CA: Sage.

Sanders, C. E., Field, T. M., Deigo, M., \& Kaplan, M. (2000). The relationship of Internet use to depression and social isolation among adolescents. Adolescence, 35, 237-241.

Sanders, C. E., Field, T. M., Diego, M., \& Kaplan, M. (2000). The relationship of Internet use to depression and social isolation among adolescents. Adolescence, 35, 237-242.

Schmitz, J. \& Fulk, J. (1991): "Organizational colleagues, media richness, and electronic mail", Communication Research, 18 (4), pp. 487-523.

Stafford, L., Kline, S. L., \& Dimmick, J. (1999, Fall). "Home e-mail: Relational maintenance and gratification opportunities." Journal of Broadcasting \& Electronic Media, 43, 4, 659663.

Tanaka, K. (2002): "Small talk with friends and family: Does text messaging on the mobile telephone help users enhance relationships", University of Washington, pp. 48-54.

Thompson, T. L., \& Zerbinos, E. (1995). Gender roles in animated cartoons: Has the picture changed in 20 years? Sex Roles, 32(9/10), 651-673.

Turkle, S. (1996). Virtuality and its discontents: searching for community in cyberspace. The American Prospect, 24, 50-57.

Valkenburg, P.M., Cantor, J., \& Peeters, A. L. (2000). Fright reactions to television: A child survey. Communication Research, 27, 82-99.

Van Evra, J. (1990). Television and Child Development. Lawrence Erlbaum Associates. 
von Feilitzen, C. (1999). Children's amount of TV viewing: Statistics from 10 countries. In C. von Feilitzen \& U. Carlsson (Eds), Children and media: Image, education, participation (pp. 61-67). Goteborg, Sweden: Goteborg University, UNESCO International Clearinghouse on Children and Violence on the Screen.

Vygotsky, L. (1986). Thought and Language. Boston: MIT Press.

Vygotsky, L. S. (1978). Mind in Society. Cambridge, MA: Harvard University Press.

Watt, D. \& White, J.M. (2000). Computers and the family life: A family development perspective. Journal of Comparative Family Studies, 30, 5-26.

Whang, L. S., \& Jang, G. Y. (2002). A Psychological Analysis of Online Game Space Its Users. Proceedings of Human Computer Interaction Conference (1), Korea, 81- 90.

Wright, J. C., Huston, A. C., Reitz, A. L., \& Piemyat, S. (1994). Young children's perceptions of television reality: determinants and developmental differences. Developmental Psychology, 30, 229239.

Young, K. S. (2004). Internet Addiction: A New Clinical Phenomenon \& its Consequences. American Behavioral Scientist. Vol. 48, No. 4, 402-415.

Young, K. S., Griffin-Shelley, E., Cooper, A., O'Mara, J., \& Buchanan, J. (2000). Online infidelity: A new dimension in couple relationships with implications for evaluation and treatment. In A. Cooper (Ed.), Cybersex: The dark side of the force (pp. 59-74). Philadelphia: Brunner Routledge.

About the authors:

Santha Kumari.

M A and Ph.D. in Psychology, Associate Professor of Psychology, School of Management \& Social Sciences, Thapar University, Patiala, India

Area of Specialization: Cognitive Psychology

Current interests: Cognitive and affective development, Emotional intelligence, Gender differences in cognition, Laterality and hemispheric specialization, Spatial abilities

Published research papers in refereed International and Indian journals of repute such as Perceptual and Motor Skills, Psychologia, Psychological studies etc. 
Completed several sponsored research projects on handedness and spatial ability , sex differences in cognition, hemispheric specialization for motor abilities, masculinity-femininity, and Cognitive microgenesis funded by Govt. Of India

Simerpreet Ahuja

M A. in Psychology. P.G. Diploma in Guidance \& Counseling and Pursuing Ph.D. in Psychology; Lecturer in Psychology/ Research Scholar in Psychology, School of Management \& Social Sciences,

Thapar University, Patiala, India

Area of Specialization: Child Development \& Counseling

Current interests: Emotional intelligence, Emotional Stability, Gender differences in affective processes.

Published research paper in refereed Indian journal of repute Psychological studies. 